\title{
Information Visualization of Lesson Study Activity
}

\author{
Murein Miksa Mardhia, Ahmad Azhari, Ardiansyah \\ Informatics Engineering, Faculty of Industrial Technology, Universitas Ahmad Dahlan \\ 3rd Campus, Prof. Dr. Soepomo, S.H. Umbulharjo Street, Yogyakarta 55161 \\ murein.miksa@tif.uad.ac.id, ahmad.azhari@tif.uad.ac.id, ardiansyah@tif.uad.ac.id
}

\begin{abstract}
This research explores how to design an interface dashboard to visualize information about evaluation activities occurred during lesson study. Data were collected in two stages using interview and questionnaire techniques whom the respondents were experts and team teaching who had been experienced the whole activities of Lesson Study. We conducted a case study in Mathematics Education Program of Universitas Ahmad Dahlan, where the teaching staffs have participated and conducted the Lesson Study activities for more than two semesters. The interface dashboard prototype was tested by conducting User Experience method and Software Usability Testing assessment. Results obtained show a fairly good acceptance level qualitatively and so does from SUS scored 75 from the average value of all participants.
\end{abstract}

Keywords: human-computer interaction; information visualization; dashboard; user experience

\section{Introduction}

Lesson study has been practically implemented in Indonesia since the last few years. This learning approach applied several processes from planning, implementation and evaluation. An evaluation system is originally designed by [1] which is aimed for knowledge management as well. In this evaluation system, work projects from participants were recorded and shared by using a Content Management System (CMS) platform. Yet, this system did not present a well-presented report about the results from each process in Lesson Study. The report itself will be beneficially used by experts and all participants to get an understanding about how good they perform and how far they possess knowledge from participating in Less on Study.

Some points to be reported i.e. how many participants have worked on class project (in percentage), how many participants attended the class, and what kind of active actions participants make during the class. Bad technique in making a report might cause these kinds of information lost. Therefore, we conducted a study to take a look about how to depict these factual data into a compact-view of visualization, yet still easy to read and has a pleasant view of aesthetics.

Lesson Study arranged between teachers are firstly observed, with the intention to find out what kind of roles they have participated on. In order to do so, we conducted a research to gain the users' satisfaction toward an information visualization for Lesson Study Evaluation which is able to visualize elements to be monitored and evaluated from Lesson Study activity.

A Teacher Evaluation System was originally introduced to a teacher learning community in Subang and Cianjur, West Java Province on behalf of joint research in topic Lesson Study. The lesson study itself consists of three main activities as follows:

Activity Plan:

1. Arranging meeting agenda

2. Choosing materials for Lesson Plan

3. Creating raw draft of Lesson Plan

4. Collecting final draft of Lesson Plan

5. Discussing Lesson Plan

6. Analysing and Testing Lesson Plan

7. Preparation of Open Lesson Activity Do:

1. Executing Open Lesson

2. Completing the observation form by participants

3. Reflection form filling by stakeholders

Activity See:

1. Preparation of Reflection 
Jurnal IImu Teknik Elektro Komputer dan Informatika (JITEKI)

Vol. 3, No. 2, Desember 2017

2. Executing the Reflection

3. Follow-up of Reflection

A framework has developed for evaluation system which summarized the activities applied in Lesson Study (depicted by Figure 1) [1]. This framework explains how activities occur within cycle from Knowledge $\rightarrow$ Presentation $\rightarrow$ Evaluation. The Knowledge part has contents that is verified by experts. This part resulted in knowledge base, which one could be created from lesson material or research papers. The knowledge base is then presented by a teacher model (guru model) whom appointed by expert. The knowledge they got during the observation in the Presentation step then being formulated in the Reflection step. If noticed from Figure 1, they added a note about 'learning process', where the knowledge hopefully transmitted into the participants during the evaluation part. This is the core of knowledge acquisition process.

Information visualization (Infoviz) field is considered as the art of data representation that easy to remodeled and learned so we can absorb useful information easily. The needs for data representation are considered huge since it also gives a big impact and value to its users, i.e. for representing route navigation as well as support a decision making.

According to [2], a dashboard is a visual display about the most wanted information to accomplish one or more goals; summarized into a single screen in order to gain an instant monitoring. Dashboard has been used in various fields or industries. Some organizational managers employ information dashboards to easily observe industrial activities such as business process, how KPI is being fulfilled, etc. Dashboard indeed helps its users in supporting decision making related to the goals of organization. These are several reasons why the numbers of research in this area is getting bigger:

1. Organizations have applied reporting technologies that reliable and want to look for more sophisticated yet still flexible.

2. The existing reporting system are not able to make a big data computation anymore

3. The common methods are getting boring, while organizations are craving for a real time and interactive ways of report.

4. Business analysts also need access into their report and analysis, yet its technologies only pleasant for people in IT backgrounds.

According to [3], crucial features commonly displayed in a dashboard are: KPI Visibility, interactivity, time frame comparison, customizable permissions, alerts and notifications, web accessibility, data integration, and native mobile apps. Information contained in a dashboard are depicted visually, as a combination of texts and pictures. Dashboard tends to load many graphics, since it can communicate more efficiently rather than a mere textual.

Furthermore, to model a data type in a visual form, [4] had shown a study literature about how to visualize data according to several methods of visualization, i.e. table, pie chart, bar chart, histogram, line chart, area chart, scatter plot, diagram Venn, Entity-Relationship Diagram (ERD), and so on.

Meanwhile to create an interactive visualization, some techniques can be implemented: zooming (in and out), overview and detailed for multidimensional data, and also Fish Eye to present a spatial information. Some main strategies of information visualization were also presented by [4], i.e. selection, linking, filtering and mapping.

A study presented in [5] discussed about an issue of data visualization that interactively associated with learning analytics from eight researches about data visualization in education topic. In order to create a learning analytics, it needs information about learning objects, learning environment, how to assess, predict and optimize them dynamically in real-time.

Visualization methods can contribute to solve many problems. By several studies conducted by [6], they tried to find values contained from visualization activity. The study discussed how visualization was considered as a part of technology, art and science. More specifically when a technology viewpoint is used, visualization can be measured from its effectivity and efficiency. Researches about visualization from its technology viewpoint should be resulted in an appropriate solution. As in technology viewpoint, it needs calculation about the cost and benefit involved. While the art and science viewpoints were considering the aesthetics and the prediction accuracy supported by related laws.

One of the purposes of information visualization is to facilitate the process of data rationalization to achieve knowledge. In order to measure how knowledge can be achieved from visualizing information, [7] demonstrated a scenario to evaluate Infoviz. As written by [7] in [8], 
they analysed evaluation scenarios from some research reports then they categorized it into two parts: scenario for understanding the data analysis and to understand visualization.

There are four scenarios to understand data analysis: a) scenario to understand the work practice, b) scenario to evaluate analysis and visual data reasoning, c) scenario to evaluate communication through visualization, and d) scenario to evaluate collaborative data analysis. While scenario to evaluate visualization, there are three scenarios: a) scenario to evaluate user performance, b) scenario to evaluate user experience, and c) scenario to evaluate visualization algorithm.

This study will focus on two parts: scenario to evaluate user performance and scenario to evaluate user experience. Where in the user experience scenario, we will focus on the activity of measure the completion time of participants to solve a task/command.

Contribution given through this research are: a) a visualization technique to monitor the Lesson Study implementation of the Reflection phase that combines contextual and temporal information; b) implementation of the design process based on user-centered design in the form of Infoviz dashboard prototype; c) qualitative and quantitative evaluation of users' satisfaction towards the dashboard visualization, the benefit and challenges faced against the solution proposed in this research.

\section{Research Method}

Many research topics contributed in this field mainly explore about human behavior toward computer or hardware related to computer. Three kinds of methods to be considered are descriptive, relational and experimental.

The dashboard development will be initiated first by conducting user profiles and user preferences toward the future interface. In order to generate a good visual of dashboard, we also need to collect data related to the knowledge we want to achieve through a dashboard. The knowledge used as the base to visualize the collected data referring to its type (nominal, ordinal or order) at the best form. The visualization is not a mere concept since we will present a prototype of Infoviz after an implementation phase is finished. There are four main steps done in this research:

1. Data gathering of User Requirement and User Profile by interview and questionnaires.

2. Mock up design and implementation

3. User Experience phase and SUS (Software Usability Testing) in about two stages.

Table 1 depict the processes performed during the research by mapping each stage with method and each result of data categorization.

Table 1. Infoviz development methods

\begin{tabular}{|c|c|c|c|}
\hline & \multicolumn{3}{|c|}{ Design Process } \\
\hline & $\begin{array}{c}\text { Pre- } \\
\text { Requirement }\end{array}$ & $1^{\text {st }}$ Iteration & $2^{\text {nd }}$ Iteration \\
\hline Method & $\begin{array}{l}\text { Survey, informal } \\
\text { interview }\end{array}$ & $\begin{array}{l}\text { Interview, } \\
\text { Usability test }\end{array}$ & $\begin{array}{l}\text { Interview, } \\
\text { Usability test }\end{array}$ \\
\hline $\begin{array}{l}\text { Number of } \\
\text { Participants }\end{array}$ & $7+1$ & 4 & 4 \\
\hline $\begin{array}{l}\text { Data Obtained } \\
\text { Type }\end{array}$ & Qualitative & $\begin{array}{l}\text { Qualitative } \\
\text { Quantitative }\end{array}$ & $\begin{array}{l}\text { Qualitative } \\
\text { Quantitative }\end{array}$ \\
\hline
\end{tabular}

\subsection{Participants Recruitment}

Object of participants selected by considering some aspects, i.e. their experience of participating in Lesson Study and the participant's expertise level of Lesson Study. In this research, we are engaging in the Lesson Study activity held by Mathematics Education Programme of Ahmad Dahlan University. By some interviews, we found out that they had conducted Lesson Study comprehensively for the last few years, where all department members are sharing the almost equal time of experience.

The evaluated teachers will be represented by lectures, which consist of 35 personnel in the range of 27-50 years old. We asked them several questions and statements about their experience in Lesson Study through interview and questionnaires. They commonly used technology for communication, presentation and accessing websites related to their field. We also asked what 
tools they used for Lesson Study activity. More than $50 \%$ of participants answered hardware such as laptops, smartphones, and software apps such as Office, Gmail and Whatsapp. About 2-5 respondents wrote that they also used tablet and screen projector to support multimedia.

\subsection{Interface Dashboard Implementation}

In order to actualize the proposed solution, we utilize software Tableau as a tool for the implementation phase. In this step, we faced some challenges to accomplish, i.e. how to balance the resources spent during implementation to visualize the whole information and functionalities. Tableau enables us to visualize such information in the form of charts as we desired, depends on the data source types.

Tableau has provided us a powerful help so simpler and faster steps could be made, so that we can spend less time and effort during the production phase. Tableau is publicly available for visualizing a huge number of data into a compact screen of dashboard yet still maintain the interactive way.

\subsection{Testing Methods}

During the experiments stage, we will fully involve participants as mentioned in the concept of user-centred design. For a reminder, we keep remind the participants that we are testing the software, not the users. This statement is used to convince users so that they don't need to worry about making mistakes. Results obtained from User Experience test are mostly subjective. Nevertheless, the objective point will remain exist such the users' reaction recorded by sensor, as study said in [7]. In this research, we are trying to produce a qualitative and quantitative results during the User Experience test. We record and observe whenever an interaction is created by participants since the first time they deal with the dashboard and after they complete the tasks asked during the testing phase. Furthermore, we also applied a Software Usability Score (SUS) test to get a semi-quantitative assessment about their satisfaction level while engaging in the dashboard.

\section{Results and Analysis}

\subsection{Requirement Analysis}

Define abbreviations and acronyms the first time they are used in the text, even after they have been defined in the abstract. Abbreviations such as IEEE, SI, MKS, and CGS do not have to be defined. Do not use abbreviations in the title or heads unless they are unavoidable. The information requirements gathering is focused by conducting informal interviews and questionnaires toward the experts and some lecturers in the team.

From the interview session, we can identify that Mathematics Education Programme had organized Lesson Study activity for more than two semesters during the year 2016-2017. When a Lesson Study activity is held, all activities are evaluated through oral discussion right after it ended. Not all members can check how much they got and learned, because there are neither reporting about the results from each activity nor information about overall presentation to be published yet.

We concluded an almost the same situation with the report studied by [9], where undefined standard of procedures were existed, in terms of quality measurements in Lesson Study. Several questions were added in the second interview to find out from participants what aspects can be considered to evaluate in Lesson Study. We raise some ideas to collect data about the participants' work assessment, quality measurement and the continuity of Lesson Study decision making. To do so, we then begin to propose our idea of enhancing the evaluation method by creating a report visually.

Through the questionnaire, participants were asked about what role they have tried and how to evaluate the activity and participants joined during the Lesson Study activity. They answered if all members have experienced as the model teacher (guru model) at least once, also as the observer (common participants). While the evaluation part, they admitted that there is no particular procedures to do so, since the Reflection activity was solely consist of oral discussion about the whole activities with less detailed logs or records created.

Through the questionnaire techniques, we try to explore how experts determine the criteria for assessing Lesson Study. First, we offered some candidates to choose and we also looked about how they put ranks into them, based on each crucial factor. Some experts have given similar answers. We called out the best three answers that the most visible to record and visualize.

From those two techniques, we are able to analyse that: we found that there has no methods or events that teaching members in Mathematics Education Programme can employ to 
maintain the evaluation of Lesson Study activities yet. To do so, we proposed a solution by implementing an information visualization which depicts recorded data and criteria to help experts and all members assess and/or evaluate the Lesson Study they have conducted.

While the criteria itself can be summarized as member presence, members' task assessment, and members' level of action during the class. The last criteria identified as the most important aspect for expert to assess, meanwhile the presence aspect counted as the most unimportant. Those criteria being the main topic to be visualized in our interface dashboard.

\subsection{Data Visualization}

Due to lack in real data field, we then used a training data that reflects the detail components in Lesson Study during the last three periods (i.e. semester or school year) in ME Program. We included some data about students' work assessment, students' in-class activity and students' attendance. We spent most of the time during this stage to analyze the requirements into a good visualization according its type of data. Each period is also visualized by different colors to gain understanding when participants want to compare information.

Attendance data was summarized through their signature in the attendance form. The type of this data is categorized as nominal data, which is able to show through a bar chart. In the dashboard, participants should be able to get the information about how much participants attended Lesson Study in each period, so that they can compare whether the total participants is increasing. Within a bar chart, we combine the information about periods of time, occupation of participants and the total attendance.

When a Lesson Study is held, teachers should monitor how the students work. Every student need to contribute work so that their marks can be recorded. Assessment can be given by teachers for example in numbers or value indexes. We adopt the assessment methods used in ME which is in the form of value index: A, A-, B+, B, B-, C+, C, C-, D+, D, and E. The visualization beneficial to this information is depicted through a certain pie chart arranged in an $x y$ coordinate of value index and time period respectively. The size of circle shows the number of students with each index.

Next criteria to be reported is the students' in-class activity. A student is categorized as being active if he/she initiatively asks within a discussion, can solve the given problem, and lead a group. This kind of data is represented by a bar chart and line chart with the detailed name of students and their total points of activity for each period of Lesson Study.

\subsection{First Phase Iteration}

We began our user experience testing through running the first iteration. The first iteration has an intention for introducing the participants about the infoviz, after exploring the user requirements process. Experiments were carried out directly by face-to-face meeting with participants while presenting the prototype as seen in Figure 2.

During the iteration process, we tried to explore the user experience by let them 'thinking aloud' in order to create a relax situation and make the participants feel unburdened.

First, we let them fill in the form about their identity and backgrounds then we continued by asking some questions about their awareness in Lesson Study and information visualization. For each iteration, we first explain some guidelines i.e. about the tasks, what tools they can use to complete the tasks (screen, mouse, keyboard) and we also mentioned that we needed to record the time completion by each participant.

There are seven main tasks addressed for each participant in the first iteration. The tasks assignment in this iteration were aimed to get the perception of participants if the Infoviz had looked quite descriptive. Detailed tasks are mentioned as follows:

- Task 1 (t1) "Your friends ask you about what is Evaluation Lesson Study (ELS). How can you explain it?"

- Task 2 (t2) "In your opinion, what is the purpose of this page?" (You can scroll the page, but please don't click the mouse yet).

- Task 3 (t3) "(still without click) Find the number of students who attended the class in each period of LS."

- Task 4 (t4) "(you can click now) Find and compare the number of teachers who attended the class during the first and third periods of LS."

- Task 5 (t5) "Find and compare the number of students who got B marks in the second and third periods of LS."

- Task 6 (t6) "Find and compare the number of students actively asking during class discussion during the second and third periods LS." 
- Task 7 (t7) "Mention the students' name who got E marks during the first and third periods of LS?"

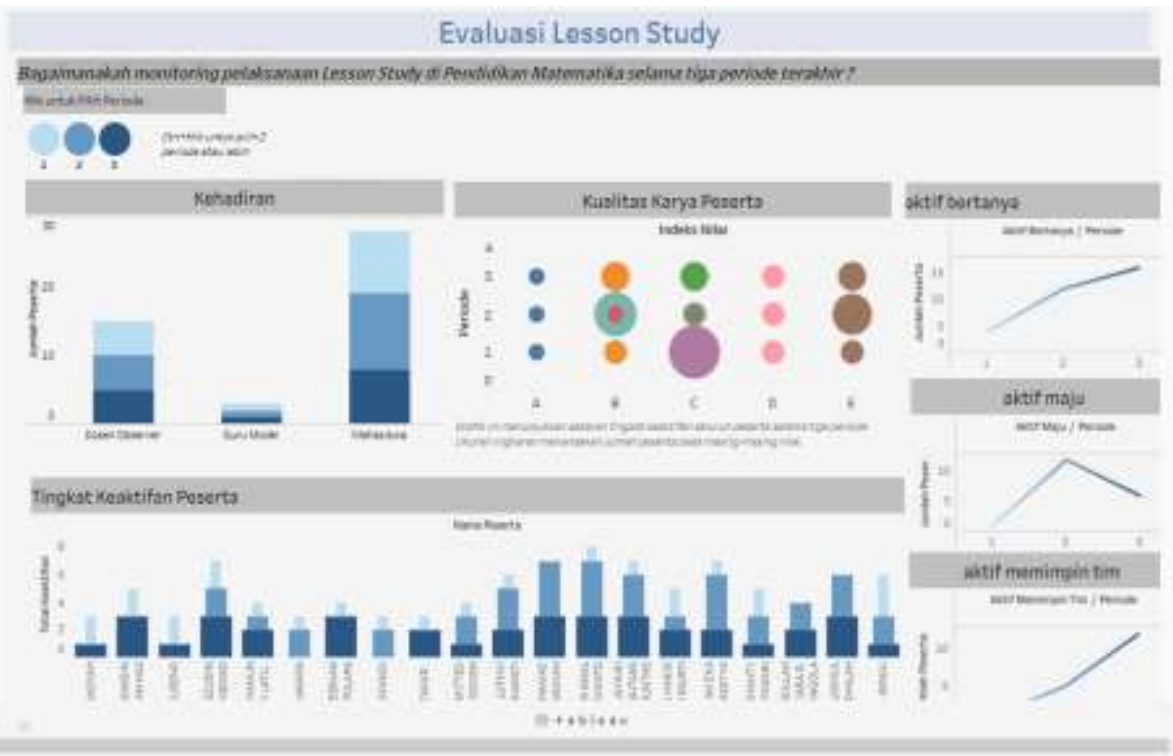

Figure 1. Interface dashboard in $1^{\text {st }}$ iteration

The first question is intentionally asked in order to let participants imagine what kind of questions will be asked next. From the interview, Participant 1 ( $p 1)$ raised a compact idea in task (t1) and (t2), compared to participant 2 (p2). Their completion time were also quite significant. We analysed them from each reaction given, (p2) spent more time in trying the dashboard by $\mathrm{him} / \mathrm{herself}$ before answering the task. While (p1) had the learning altogether with the task completion.

All participants tend to use more often 'click' rather than 'mouse hover', this phenomen on was more frequently happened during the first iteration. We analysed that participants are still in their learning phase, while some are afraid to make mistake, so we think it is reasonable. For the next tasks, ( $\mathrm{p} 1)$ and (p2) were starting to understand that they did more 'mouse hover' action rather than 'click' to gain information.

Table 2. Tasks completion time in $1^{\text {st }}$ iteration

\begin{tabular}{cccccccc}
\hline Participant & $\mathrm{t} 1$ & $\mathrm{t} 2$ & $\mathrm{t} 3$ & $\mathrm{t} 4$ & $\mathrm{t} 5$ & $\mathrm{t} 6$ & $\mathrm{t} 7$ \\
\hline p1 & $00: 36$ & $00: 36$ & $00: 35$ & $00: 54$ & $02: 02$ & $00: 27$ & $00: 40$ \\
P2 & $01: 57$ & $01: 57$ & $00: 54$ & $00: 25$ & $00: 57$ & $00: 08$ & $01: 26$ \\
P3 & $00: 45$ & $00: 10$ & $00: 24$ & $00: 12$ & $00: 54$ & $00: 15$ & $01: 18$ \\
P4 & $01: 17$ & $00: 10$ & $00: 18$ & $04: 10$ & $00: 24$ & $00: 16$ & $00: 25$ \\
Min & $00: 36$ & $00: 10$ & $00: 18$ & $00: 12$ & $00: 24$ & $00: 08$ & $00: 25$ \\
Max & $01: 57$ & $01: 57$ & $00: 54$ & $04: 10$ & $02: 02$ & $00: 27$ & $01: 26$ \\
Avg & $01: 08$ & $01: 15$ & $00: 32$ & $01: 25$ & $01: 04$ & $01: 06$ & $00: 57$ \\
Failed & 0 & 0 & 0 & 0 & 0 & 0 & 0 \\
\hline
\end{tabular}

Feedback questions were given directed to the participants: a) "How can you describe in your own simple words, how is the performance of Lesson Study in the third period if it seen from the students' value distribution?", b) "How can you describe, in your simple own words, how is the performance of Lesson Study in the third period, if seen from the students' in-class activity?", c) "Which part that you think: a. the most important, b. the most unimportant from this Infoviz?", and d) "If you have 3 chances to improve this Infoviz, what do you wish to be better, and why?"

From the questions above, ( $p 1)$ gave a feedback about enhancing contrast on text color, and also adding an information regarding the colors used in index values at the upright corner to explain more about the color area border for index (+) and (-) such as happened in B+, B- index. While by the SUS for ( $p 1$ ) through ( $\mathrm{p} 4)$ in the first iteration is shown at Table 3. According to website usability.gov [10], this score is categorized as fairly good, where success is shown by score above 68 , indicated that the interface has an above average satisfaction. 
Jurnal IImu Teknik Elektro Komputer dan Informatika (JITEKI)

Vol. 3, No. 2, Desember 2017

Table 3. Tasks completion time in $1^{\text {st }}$ iteration

\begin{tabular}{cccccccccccc}
\hline Participant & q1 & q2 & q3 & q4 & q5 & q6 & q7 & q8 & q9 & q10 & SUS \\
\hline p1 & 4 & 1 & 5 & 3 & 4 & 1 & 3 & 1 & 5 & 1 & 85 \\
p2 & 4 & 2 & 4 & 4 & 4 & 1 & 5 & 1 & 4 & 1 & 80 \\
p3 & 3 & 2 & 4 & 2 & 4 & 2 & 3 & 2 & 3 & 2 & 67.5 \\
p4 & 4 & 4 & 4 & 1 & 4 & 2 & 3 & 1 & 5 & 4 & 70 \\
\hline
\end{tabular}

Overall, from the first iteration, all participants have successfully answered the tasks with various time completion. All participants have shown a good interaction toward the dashboard and successfully reached our goal: to introduce the system. Each participant can react based on their characteristic and showed us that the dashboard had given them an ease way to gain knowledge from visualizing action and numbers.

\subsection{Second Phase Iteration}

At the second iteration, we successfully added some improvisation through the visualization which have been given by participants. The number and persona of participants were equal to the first iteration. UX observation still also performed by face-to-face (F2F) interview on behalf of Lesson Study dashboard. The interface of our Infoviz shown by Figure 3.

The difference between the first and second iteration are about the task given. We wanted to find out the learnability aspect of our interface towards participants. The shorter completion time created by participants in solving the tasks, it positively defined how well they memorize and learn the interface. The detailed tasks are mentioned as follows:

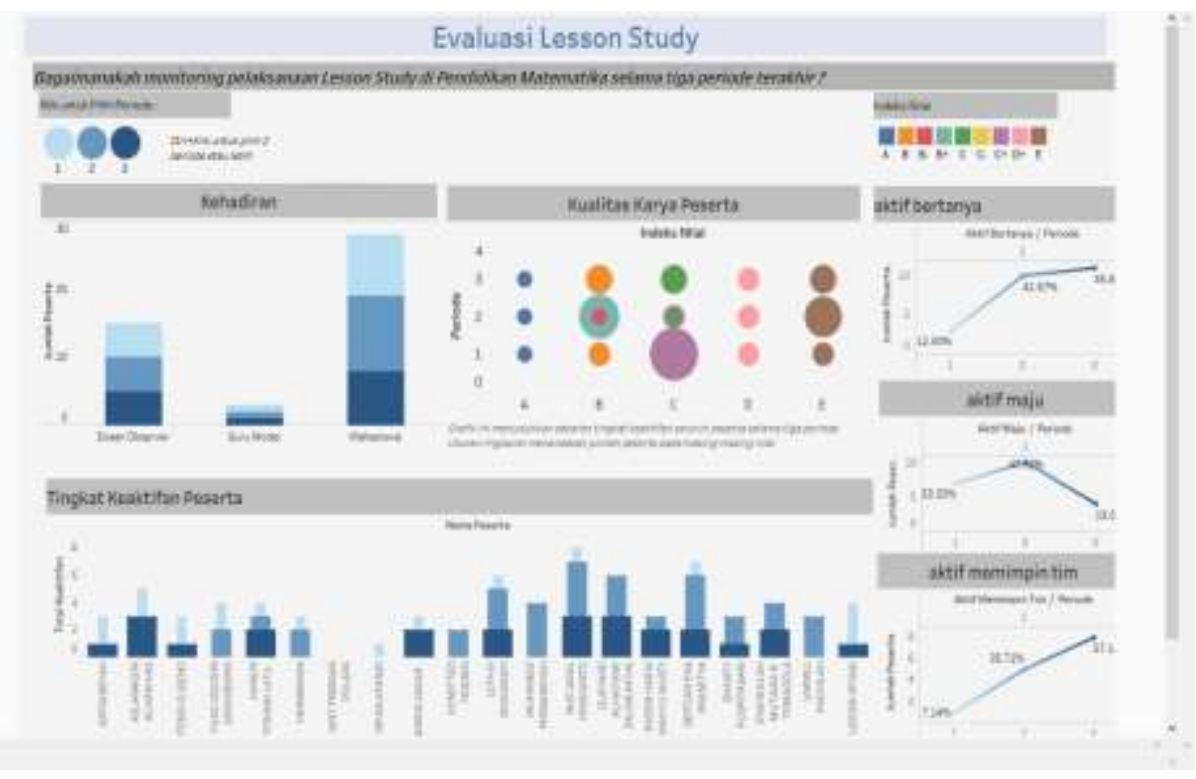

Figure 3. Interface dashboard in $2^{\text {nd }}$ iteration

- Task 1 (t1) "Your friends ask you about what is Evaluation Lesson Study (ELS). How can you explain it?"

- Task 2 (t2) "In your opinion, what is the purpose of this page?" (You can scroll the page, but please don't click the mouse yet).

- Task 3 (t3) "(still without click) Can you find the number of (observing) teacher who attended the class during the third period of LS?"

- Task 4 (t4) "(you can click now) how can you compare the number of attended teachers during the second and third periods of LS?"

- Task 5 (t5) "Please describe the level of students' liveliness during the third period of LS."

- Task 6 (t6) "Mention the students' names who got $E$ marks during the first until the third period of LS." 
Jurnal IImu Teknik Elektro Komputer dan Informatika (JITEKI)

Vol. 3, No. 2, Desember 2017

- Task 7 (t7) "Explain the difference number of students who got B marks from the first to the second period of LS?"

Table 4. Tasks completion time in $2^{\text {nd }}$ iteration

\begin{tabular}{cccccccc}
\hline Participant & $\mathrm{t} 1$ & $\mathrm{t} 2$ & $\mathrm{t} 3$ & $\mathrm{t} 4$ & $\mathrm{t} 5$ & $\mathrm{t} 6$ & $\mathrm{t} 7$ \\
\hline p1 & $01: 03$ & $00: 35$ & $00: 08$ & $00: 15$ & $00: 31$ & $00: 30$ & $01: 05$ \\
P2 & $01: 29$ & $00: 45$ & $00: 09$ & $00: 18$ & $00: 52$ & $00: 40$ & $01: 20$ \\
P3 & $00: 45$ & $00: 10$ & $00: 09$ & $00: 10$ & $00: 23$ & $00: 57$ & $00: 12$ \\
P4 & $01: 17$ & $00: 10$ & $00: 40$ & $00: 32$ & $00: 37$ & $00: 08$ & $00: 08$ \\
Min & $00: 45$ & $00: 10$ & $00: 08$ & $00: 10$ & $00: 23$ & $00: 08$ & $00: 08$ \\
Max & $01: 29$ & $00: 45$ & $00: 40$ & $00: 32$ & $02: 52$ & $00: 57$ & $01: 20$ \\
Avg & $01: 08$ & $00: 25$ & $00: 16$ & $00: 18$ & $01: 35$ & $01: 33$ & $00: 41$ \\
Failed & 0 & 0 & 0 & 0 & 0 & 0 & 0 \\
\hline
\end{tabular}

At the second iteration, all participants felt more familiar to the dashboard. They spent shorter time to scroll and click some features while trying to finish the tasks, indicated that they have more understood about the rules and tends to be more critical about charts displayed over the dashboard.

After tasks were completed, we asked questions to provoke feedback as we did previously in the first iteration. Participant 1 (p1) commented about the visualization that getting more informative than before, seen from the added legend about colour area in value index of tab Students' Work Assessment (Hasil Karya Peserta). While participant 2 (p2) mentioned a feedback to replace the line chart visualization in tab Activity Type (Jenis Keaktifan) on the right side. According to (p2), teachers and experts are also need the information that displays the total percentage of active students compared to the total students attended. (p2) gave a suggestion to replace the current chart with a pie chart of percentage.

Table 5. Usability testing result in $2^{\text {nd }}$ iteration

\begin{tabular}{cccccccccccc}
\hline Participant & q1 & q2 & q3 & q4 & q5 & q6 & q7 & q8 & q9 & q10 & SUS \\
\hline p1 & 4 & 5 & 5 & 3 & 3 & 1 & 3 & 1 & 5 & 5 & 62.5 \\
p2 & 4 & 1 & 5 & 2 & 4 & 1 & 5 & 2 & 5 & 1 & 92.5 \\
p3 & 4 & 2 & 4 & 1 & 4 & 1 & 4 & 2 & 4 & 2 & 80 \\
p4 & 4 & 4 & 5 & 1 & 5 & 2 & 2 & 1 & 5 & 4 & 65 \\
\hline
\end{tabular}

If we observed through the average completion time of all participants and the answer they had successfully given, ( $\mathrm{p} 1$ ) through (p4) have shown a good level of learnability. A positive feedback was also shown from (p1) that asked if the dashboard is already installed to be applied in their next Lesson Study activity.

Meanwhile the Software Usability Score (SUS) results showed for (p1) through (p4) after the second iteration was explained in Table 5. The average score of the second iteration SUS was 77.5. User's incorrect filling or increased expectation can be considered for decreasing score in this iteration. It also gives us motivation to encourage the dashboard in way of more sophisticated features and interactivity.

\section{Conclusion}

During this study we have presented an information visualization of Lesson Study Evaluation. We also have utilized contextual and temporal information into the Infoviz. By conducting user experience, our participants able to determine their level of learnability and usability, which means the Infoviz was able to be learnt quickly.

Improvements feedback from participants can be implemented easily and quickly, so that it could be concluded as a positive way of user's satisfaction. The number of improvements and the time completion spent by all participants got less for each iteration, which also being observed from the SUS score. The average score of SUS reached 75, which according to [10], means above the average. 


\section{References}

[1] M. M. Mardhia, A. Z. R. Langi, and Y. Bandung, "Knowledge management system development with evaluation method in lesson study activity," in Proceedings - ICACSIS 2014: 2014 International Conference on Advanced Computer Science and Information Systems, 2014, pp. 482-487.

[2] S. Few, "Information Dashboard Design," Eff. Vis. Commun. data Sebastopol, no. January, p. 223, 2006.

[3] "Top Dashboard Software - 2017 Reviews \&amp; Pricing." [Online]. Available: http://www.softwareadvice.com/bi/das hboard-comparison/\#buyers-guide. [Accessed: 26Jan-2017].

[4] M. Khan and S. Khan, "Data and information visualization methods, and interactive mechanisms: A survey," Int. J. Comput. Appl., vol. 34, no. 1, pp. 1-14, 2011.

[5] D. Ifenthaler, B. E. Benjamin Erlandson, and D. Ifenthaler dirk, "Learning with Data: Visualization to Support Teaching, Learning, and Assessment," Tech Know Learn, vol. 21, pp. 1-3, 2016.

[6] van Wijk, J. J. (n.d.). The Value of Visualization. In VIS 05. IEEE Visualization, 2005. (pp. 79-86). IEEE. https://doi.org/10.1109/VISUAL.2005.1532781

[7] H. Lam, E. Bertini, P. Isenberg, C. Plaisant, and S. Carpendale, "Empirical studies in information visualization: Seven scenarios," IEEE Transactions on Visualization and Computer Graphics, vol. 18, no. 9. pp. 1520-1536, 2012.

[8] A. Yahya, "Visuäly : Visualizing the Condition of Älynysse Bus," University of Tampere, 2015.

[9] Á. F. Agudo-Peregrina, S. Iglesias-Pradas, M. Á. Conde-González, and Á. HernándezGarcía, "Can we predict success from log data in VLEs? Classification of interactions for learning analytics and their relation with performance in VLE-supported F2F and online learning," Comput. Human Behav., vol. 31, no. 1, pp. 542-550, 2014.

[10] "System Usability Scale (SUS) I Usability.gov." [Online]. Available: https://www.usability.gov/how-to-and-tools/resources/templates/system-usability-scalesus.html. [Accessed: 20-Oct-2017]. 